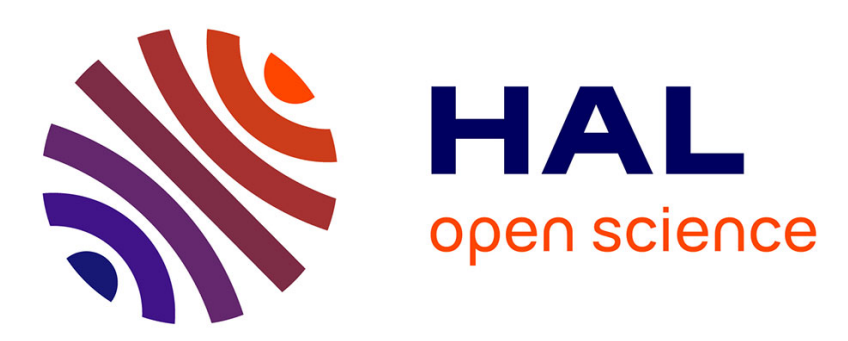

\title{
Formation mechanism of transparent Mo6 metal atom cluster film prepared by electrophoretic deposition
}

\author{
T.K.N. Nguyen, B. Dierre, F. Grasset, A. Renaud, Stéphane Cordier, P.
}

Lemoine, N. Ohashi, T. Uchikoshi

\section{- To cite this version:}

T.K.N. Nguyen, B. Dierre, F. Grasset, A. Renaud, Stéphane Cordier, et al.. Formation mechanism of transparent Mo6 metal atom cluster film prepared by electrophoretic deposition. Journal of The Electrochemical Society, 2017, 164 (7), pp.D412-D418. 10.1149/2.0591707jes . hal-01544457

HAL Id: hal-01544457

https://hal-univ-rennes1.archives-ouvertes.fr/hal-01544457

Submitted on 29 Oct 2020

HAL is a multi-disciplinary open access archive for the deposit and dissemination of scientific research documents, whether they are published or not. The documents may come from teaching and research institutions in France or abroad, or from public or private research centers.
L'archive ouverte pluridisciplinaire HAL, est destinée au dépôt et à la diffusion de documents scientifiques de niveau recherche, publiés ou non, émanant des établissements d'enseignement et de recherche français ou étrangers, des laboratoires publics ou privés. 


\title{
Formation Mechanism of Transparent Mos Metal Atom Cluster Film Prepared by Electrophoretic Deposition
}

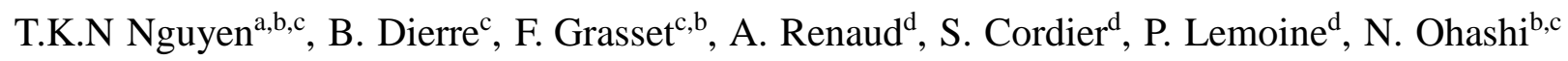
and T. Uchikoshi ${ }^{\mathrm{a}, \mathrm{b}, \mathrm{c}, *}$

${ }^{\mathrm{a}}$ Graduate School of Chemical Sciences and Engineering, Hokkaido University, Sapporo, Japan.

${ }^{b}$ Research Center for Functional Materials, National Institute for Materials Science, Tsukuba, Japan.

${ }^{c}$ Laboratory for Innovative Key Materials and Structures, UMI_3629 CNRS- Saint-GobainNIMS, NIMS, Tsukuba, Japan

${ }^{\mathrm{d}}$ Institute of Chemical Sciences of Rennes, UMR 6226 CNRS- University of Rennes 1, France.

*E-mail address of corresponding author: UCHIKOSHI.Tetsuo@ nims.go.jp

\begin{abstract}
Among the solution deposition techniques, electrophoretic deposition (EPD) is a fairly rapid and low cost two-step process well-known for ceramic shaping and conductive surface coating. Recently we have reported the fabrication of transparent inorganic thin film composed of octahedral molybdenum clusters and shown that the stabilization of the cluster solutions during EPD is very important to obtain high quality films. In this study, we selected the $\mathrm{Cs}_{2} \mathrm{Mo}_{6} \mathrm{Br}^{\mathrm{i}}{ }_{8} \mathrm{Br}^{\mathrm{a}}{ }_{6}$ or $\left(\left(\mathrm{n}-\mathrm{C}_{4} \mathrm{H}_{9}\right)_{4} \mathrm{~N}\right)_{2} \mathrm{Mo}_{6} \mathrm{Br}^{\mathrm{i}}{ }_{8} \mathrm{Br}_{6}^{\mathrm{a}}{ }_{6}$ clusters compound $\left({ }^{\mathrm{i}}=\right.$ inner ligands, ${ }^{\mathrm{a}}=$ apical ligands $)$ as precursors in a Methyl Ethyl Ketone (MEK) solution to fabricate the inorganic Mo $\mathrm{Mo}_{6}$ cluster transparent film on a conductive indium tin oxide (ITO) glass substrate. For the first time, the mechanism for the deposition process of metal clusters is proposed based on results obtained by the combination of complementary techniques such as infrared spectroscopy, X-ray analysis and electron microscopy. The $\mathrm{Mo}_{6}$ film on the ITO glass substrate exhibiting a Br-rich layer is quickly deposited during the first stage of the EPD followed by a multilayer structure consisting of two types of cluster compounds, [ $\left.\mathrm{Mo}_{6} \mathrm{Br}_{8}{ }_{8} \mathrm{Br}_{4}{ }_{4}\left(\mathrm{H}_{2} \mathrm{O}\right)^{\mathrm{a}}{ }_{2}\right]$ and $\left(\mathrm{H}_{3} \mathrm{O}\right)_{2}\left[\mathrm{Mo}_{6} \mathrm{Br}_{8}{ }_{8} \mathrm{Br}_{4}^{\mathrm{a}}(\mathrm{OH})_{2}^{\mathrm{a}}{ }_{2}\right.$.
\end{abstract}

Keyword: Metal atom cluster, molybdenum halides, electrophoretic deposition 


\section{Introduction}

The octahedral molybdenum halide cluster has been extensively studied since the 1970s after the discovery in 1971 of the $\mathrm{A}_{\mathrm{y}} \mathrm{Mo}_{6} \mathrm{Q}_{8}(\mathrm{Q}=$ chalcogen, $\mathrm{A}=$ cation $)$ compounds, the so-called "Chevrel phases"1,2. More recently, their high potential use in nanoarchitectonic devices has been reported ${ }^{3-5}$. The $\left[\mathrm{Mo}_{6} \mathrm{Br}_{8}{ }_{8} \mathrm{Br}^{\mathrm{a}}{ }_{6-\mathrm{x}} \mathrm{L}_{\mathrm{x}}^{\mathrm{a}}\right]^{\mathrm{x}-2}$ cluster unit, based on the $\left[\mathrm{Mo}_{6} \mathrm{X}_{8}^{\mathrm{i}}\right]^{\mathrm{x}+}$ core family $\left(\mathrm{X}^{\mathrm{i}}=\mathrm{Br}\right.$, $\mathrm{Cl}$, I at face-capping inner position) capped by 6 halogens or functional groups at the terminal apical position $\left(\mathrm{L}^{\mathrm{a}}=\text { donor ligand; } \mathrm{Br}, \mathrm{Cl}, \mathrm{I}, \mathrm{OH}, \mathrm{H}_{2} \mathrm{O}, \mathrm{CF}_{3} \mathrm{COOH}, \ldots\right)^{2,5}$, has recently been studied in applications of $\mathrm{pH}$-sensor ${ }^{6}$, singlet oxygen sensitization ${ }^{7}$, photocatalytic reactions $\mathrm{s}^{4,8}$, solar cells $^{9-11}$ or biotechnology ${ }^{12-18}$. The synthesis of hybrid nanocomposites based on metal atom clusters has also attracted the interest in optoelectronic applications ${ }^{4}$, but only a few studies have reported the preparation of transparent thin films ${ }^{19-21}$.

The surface of glass is often coated for intrinsic reasons (safety, convenience or better stability) or specific functionalization (ultraviolet or heat protection), water-repellent coating, shatter protection, easy-to-clean and self-cleaning coatings ${ }^{22-25}$. As a method for these applications, electrophoretic deposition (EPD) would be an attractive process for preparing transparent, smooth and thickness-controlled thin coating. In addition, this process can be easily scalable to an industrial level. The EPD process consists of two steps: i) the electrophoresis of charged particles moving toward the electrode under an electric field, and ii) the deposition of the particles on the electrode surface by coagulation ${ }^{26-28}$. Our group has recently reported the fabrication of transparent inorganic thin films composed of octahedral molybdenum metal clusters deposited on indium tin oxide (ITO) glass slides by EPD ${ }^{21}$. In the study, $\mathrm{Cs}_{2} \mathrm{Mo}_{6} \mathrm{Br}_{14}$ cluster compound was dissolved in various solvents to prepare the EPD solutions. The films exhibit a high transparency in the visible light wavelength range and good absorption at wavelengths lower than $400 \mathrm{~nm}$ and higher than $1100 \mathrm{~nm}$, which is of significant interest for ultraviolet (UV) and/or near infrared (NIR) cut filter applications, such as windows and solar concentrators ${ }^{29-39}$. Moreover, a luminescent emission in the wavelength range of 650 to $900 \mathrm{~nm}$ resulting from the Mo 6 cluster units could be observed and depends on the EPD solutions and conditions. The efficiency and lifetime of the luminescent emission of the molybdenum halide cluster depend on the lowest excited state determined by the prominent improvement of the halides ${ }^{40}$. The electronic interaction between the ligands of the $\left.\left[\mathrm{Mo}_{6} \mathrm{X}_{8} \mathrm{~L}_{6}\right]^{2}\right]^{2-}$ clusters in the network and different kinds of cations depends on the fabrication process of the metal cluster for films, crystals, powders or composites $^{4,9,41}$.

From the results of the previous report, Methyl Ethyl Ketone (MEK) was evidenced as the stably dispersing medium in order to remain the original luminescent characterization of the $\mathrm{Cs}_{2} \mathrm{Mo}_{6} \mathrm{Br}_{14}$ cluster precursors ${ }^{21}$. In this study, we used $\mathrm{TBA}_{2} \mathrm{Mo}_{6} \mathrm{Br}_{14}$ (TBA $=$ Tetra Butyl Ammonium, $\left.\left(\left(\mathrm{n}-\mathrm{C}_{4} \mathrm{H}_{9}\right)_{4} \mathrm{~N}\right)\right)$ and $\mathrm{Cs}_{2} \mathrm{Mo}_{6} \mathrm{Br}_{14}$ as the raw materials. The main objectives are to (i) select the best cluster precursor in order to obtain good quality $\mathrm{Mo}_{6}$ cluster films and (ii) evaluate 
the stability of the $\mathrm{Cs}_{2} \mathrm{Mo}_{6} \mathrm{Br}_{14}$ and $\mathrm{TBA}_{2} \mathrm{Mo}_{6} \mathrm{Br}_{14}$ cluster compounds in Methyl Ethyl Ketone (MEK). Indeed, in MEK solution, the $\mathrm{Br}^{-}$ligands may be partially replaced and released out of the octahedral cluster during the dissolving and depositing procedures. The deposition mechanism to fabricate a transparent Mo6 cluster film by the EPD process and the structure of the obtained film were studied for the first time as far as we know by using complementary tools and techniques; i.e., color 3D laser microscopy, field-emission scanning electron microscopy (FE-SEM), X-ray diffraction (XRD), scanning transmission electron spectroscopy (STEM), transmission electron spectroscopy-energy dispersive spectroscopy (TEM-EDS), Fourier transform infrared spectroscopy (FTIR), X-ray fluorescence spectroscopy (XRF) and X-ray photoelectron spectroscopy (XPS).

\section{Experimental}

\section{Preparation of cluster films by EPD}

The $\mathrm{Cs}_{2} \mathrm{Mo}_{6} \mathrm{Br}_{14}$ powder $(\boldsymbol{C M B P})$ was synthesized from $\mathrm{MoBr}_{2}$ and $\mathrm{CsBr}$ agents by a solid-state method at high temperature, while the (TBA) ${ }_{2} \mathrm{Mo}_{6} \mathrm{Br}_{14}$ powder $(\boldsymbol{T M B P})$ was prepared from $\boldsymbol{C M B P}$ and $\mathrm{TBABr}$ agents by solution chemistry ${ }^{42}$. Both powders were separately dissolved in reagent grade methyl ethyl ketone (MEK) (99\%, Nacalai Tesque, Inc., Kyoto, Japan) at the concentration of $5 \mathrm{~g} / \mathrm{L}$ with agitating by a magnetic stirrer for 20 minutes. ITO glass, washed with distilled water and acetone during ultrasonication, was connected to a Keithley Model 2400 Series Source meter as the anodic substrate and a stainless steel sheet as the cathode. Based on our previous study ${ }^{21}$, the voltage from 7.5 to $25 \mathrm{~V}$ and deposition time up to 40s were applied. The best quality $\mathrm{Cs}_{2} \mathrm{Mo}_{6} \mathrm{Br}_{14}$ films (CMBF) and $\mathrm{TBA}_{2} \mathrm{Mo}_{6} \mathrm{Br}_{14}$ films (TMBF) were obtained by applying voltages at 13 and $17 \mathrm{~V}$, respectively. The Mo 6 cluster-based films deposited on the ITO glass substrates, whose surface area were about $1 \times 1.5 \mathrm{~cm}^{2}$, were characterized after drying in air for $24 \mathrm{~h}$.

\section{Characterization methods}

The zeta potential and electric conductivity of the suspensions were measured by a zeta-potential analyzer (Malvern Instrument, Ltd., Zetasizer Nano Z). The particle size of the cluster in an MEK suspension was measured by a dynamic light scattering (DLS) technique using a Nano Q V2.5.9.0 analyzer (Cordouan Technologies) at the wavelength of $657 \mathrm{~nm}$. A high resolution color 3D laser microscope with a $408 \mathrm{~nm}$ laser was used for the measurement of the thickness of the films formed at different deposition times. The surface morphology of the thin films was observed by an FE-SEM (Hitachi S4800). The crystallographic structure of the films was determined by XRD (SmartLab, RIGAKU, $40 \mathrm{kV}$ and $30 \mathrm{~mA}$ ) in the $2 \theta$ angle range from $5^{\circ}$ to $55^{\circ}$ and at the scan speed of $1 \%$ min with $\mathrm{Cu} \mathrm{K}_{\alpha}$ radiation $(\lambda=1.54 \AA)$. The chemical state and composition were verified by coupling several techniques, such as FTIR (Thermoscientific Nicolet 4700) in the wavenumber range from 4000 to $400 \mathrm{~cm}^{-1}$ and XRF measurement (EZX 
Primus II, Rigaku). XPS spectra of the powder and film were measured by a PHI Quantera SXM (ULVAC-PHI) using $\mathrm{Al} \mathrm{K}$ radiation at $20 \mathrm{kV}$ and $5 \mathrm{~mA}$, neutralization by $\mathrm{Ar}^{+}$, pass energy of $55 \mathrm{eV}$ and the take-off angle of $45^{\circ}$. High resolution observation of the cluster-deposited films was performed by a TEM (JEOL JEM 2100F) equipped with an EDS analysis device.

\section{Results and discussion}

\section{Characterization of the solutions:}

The $\boldsymbol{C M B P}$ and $\boldsymbol{T M B P}$ cluster-containing suspensions in the MEK solvent presented an electric conductivity of approximately $0.3 \mathrm{mS} / \mathrm{cm}$ and a negative zeta potential in the range of $20-25 \mathrm{mV}$ as listed in Table. 1. These values are slightly different compared to those in our previous study. It is related to the stirring time, which was optimized in order to achieve a good colloidal liquid and a thick film by the EPD. The dissolution of $\boldsymbol{T M B P}$ in MEK is quicker than for $\boldsymbol{C M B P}$ due to the better compatibility of the $\mathrm{TBA}^{+}$cation in an organic solvent. Nevertheless, the hydrodynamic diameters of the $\boldsymbol{C M B P}$ and $\boldsymbol{T M B P}$ clusters in the MEK solution (1g/L) obtained by DLS were in the same range of $11 \pm 1$ and $13 \pm 1 \mathrm{~nm}$, respectively (Table 1 ). It could correspond to an aggregate of less than $1000\left[\mathrm{Mo}_{6} \mathrm{Br}_{8}{ }_{8} \mathrm{Br}_{6}^{\mathrm{a}}\right]^{2-}$ cluster units ${ }^{42}$.

\section{Structural and chemical characterization of the film:}

In order to discuss the deposition process, the chemical composition and structure were analyzed for the CMBF and TMBF films prepared at different voltages and deposition times. The Br/Mo atomic ratios evaluated by XRF of the $\mathrm{Mo}_{6}$ cluster-based films obtained by the EPD as a function of the deposition time and applied voltage are shown in Figure 1. At 13V, which was used for the CMBF, was applied to TMBF, a good homogeneity was not obtained because the film was easily broken by the re-dissolution in the MEK solution after stopping the applied voltage. The Br/Mo atomic ratio as a function of the deposition time were determined at $13 \mathrm{~V}$ for CMBF and $17 \mathrm{~V}$ for TMBF, which are the optimal voltages to attain the best uniformity in the films, respectively, for those as a function of the applied voltage at 10s for both CMBF and TMBF.

The atomic ratios of the $\mathrm{Br}$ and $\mathrm{Mo}$ atoms were estimated to be $2.20( \pm 0.11)$ and $2.25( \pm 0.13)$ for the $\boldsymbol{C M B P}$ and $\boldsymbol{T M B P}$, respectively, which were in fairly good agreement with the theoretical value of 2.33 (14 $\mathrm{Br}$ atoms/6 Mo atoms). In addition, the $\mathrm{Cs}^{+}$atoms were detected in $\boldsymbol{C M B P}$ solution, but it was not possible to measure any signal showing the existence of Cs atoms in all of the CMBF films, suggesting the absence of the $\mathrm{Cs}^{+}$cations in the electrodeposited films.

The curves in Fig.1a show a decrease in the Br/Mo atomic ratio of the films from $7.2( \pm 0.3)$ (TMBF) or $4.9( \pm 0.2)(\mathbf{C M B F})$ to $2.8( \pm 0.2)$ in the first 10 s when the applied voltage increased from 7.5 to $25 \mathrm{~V}$. These values are much higher than the theoretical value (2.33) and the experimental values determined for $\boldsymbol{C M B P}$ and $\boldsymbol{T M B P}$, suggesting that the Br-atom rich Mo6 cluster layers are preferentially deposited on the ITO glass for the first 10s, especially at the low 
applied voltages.

In a similar way, the $\mathrm{Br} / \mathrm{Mo}$ atomic ratio decreases to the theoretical index (2.33) for the higher deposition time (at a fixed applied voltage) and reaches the theoretical value after 30s (TMBF) or 40s (CMBF) of the deposition. These data also indicate that a Br-rich layer containing Mo6clusters is deposited during the first seconds of the EPD process, followed by the deposition of the Mo6-cluster units. One explanation of these two steps during the deposition process can be expressed as follows: During the dissolution process, the free $\mathrm{Br}^{-}$anions are generated by the substitution of the solvent molecules to form $\left[\mathrm{Mo}_{6} \mathrm{Br}^{\mathrm{i}}{ }_{8 \mathrm{Br}^{\mathrm{a}}}{ }_{6-\mathrm{x}}(\text { solvent })_{\mathrm{x}}^{\mathrm{a}}\right]^{\mathrm{x}-2}$ cluster units, then move toward the electrode faster than the bigger $\left[\operatorname{Mo}_{6} \mathrm{Br}_{8}{ }_{8} \mathrm{Br}^{\mathrm{a}}{ }_{6-\mathrm{x}}(\text { solvent })^{\mathrm{a}}{ }^{\mathrm{x}}\right]^{\mathrm{x}-2}$ cluster units under the impact of an electric field.

Considering the $\mathrm{Br} / \mathrm{Mo}$ atomic ratio of $\mathbf{C M B F}$ and $\mathbf{T M B F}$ versus the applied voltage and deposition time, the EPD parameters were selected to obtain the $\mathrm{Mo}_{6}$-cluster films with a $\mathrm{Br} / \mathrm{Mo}$ atomic ratio close to the theoretical one (2.33); i.e., the deposition time was longer than $20 \mathrm{~s}$, and the voltage fixed at $13 \mathrm{~V}$ for $\mathbf{C M B F}$ and $17 \mathrm{~V}$ for TMBF.

The thickness of the Mo6 cluster films prepared from the $\boldsymbol{C M B P}$ and $\boldsymbol{T B M P}$ suspensions in the MEK solution at the different deposition times of 10, 20,30 and 40 seconds was measured using a color 3D microscope as presented in Table.2. The average values were recorded at least on three samples and three positions on each films. It can be seen that $\mathbf{C M B F}$ reached a maximum thickness of $1.89 \pm 0.08 \mu \mathrm{m}$ for the deposition time of $40 \mathrm{~s}$ (applied electric field of $13 \mathrm{~V}$ ), while TMBF presented a maximum thickness of $1.68 \pm 0.07$ after $30 \mathrm{~s}$ of the deposition. For higher deposition at $40 \mathrm{~s}$, the thickness of the TMBF sample decreased. Such phenomena was previously reported for $\mathbf{C M B F}^{21}$ and was explained by the fact that the deposited Mo6 film on the ITO glass with a high thickness plays the role as a resistance layer and then reduces the influence of the electric field on the movement of further cluster particles. Moreover, the diffusion of cations to the outside cluster layer will break up the balance of anion cluster particles with the charge on the electrode. Consequently, the $\mathrm{Mo}_{6}$ cluster units will be released out of the layer by the re-dissolution in the MEK solution after $40 \mathrm{~s}$ for the TMBF film. Considering these results, the use of $\boldsymbol{C M B P}$ for fabricating the Mo6 cluster thin film seems to be better for controlling the thickness of the Mo6 cluster-deposited films.

The surface morphology of the Mo6 cluster films was characterized by SEM on the 20s deposition time samples. The SEM images of the CMBF20s and TMBF20s films show the evidence of homogeneous and flat morphology area of the film even at low magnifications of 1000 and 50000 times (Fig. 2a). However, the surface of the film seems not to be stable under high vacuum because many hairline cracks with $500 \mathrm{~nm}$ widths were observed. Such cracks are probably generated on the smooth surface of the films by the quick evaporation of the absorbed water molecules or residual solvent, especially during the evacuation in the SEM chamber. The cross- 
sectional SEM images of the high resolution images of the CMBF20s and TMBF20s films shown in Fig. $2 \mathrm{~b}$ exhibit a layered structure formed on the glass matrix, the ITO layer $(0.2 \mu \mathrm{m})$ and the Mo6-cluster layer $(\sim 1.2 \mu \mathrm{m})$. These values are in good agreement with the color 3D microscope results. A larger view of the cross-section of the CMBF40s film confirmed the homogeneity of the deposition process and also the thickness could reach $2 \mu \mathrm{m}$ as shown in Figure $2 \mathrm{c}$ at $40 \mathrm{~s}$.

The XRD patterns of the $\boldsymbol{C M B P}$ and $\boldsymbol{T M B P}$ powder samples, the CMBF30s and TMBF30s film samples and the ITO substrate are shown in Figure 3. The $\boldsymbol{C M B P}$ and $\boldsymbol{T M B P}$ patterns present a series of sharp peaks exhibiting a strong intensity from $7^{\circ}$ to $55^{\circ}$ that indicates the good crystallinity of the precursors. In the opposite, the CMBF30s and TMBF30s samples present the broad peak at the $2 \theta$ angle of $11^{\circ}$, not assigned to the ITO glass substrate, suggesting a low crystallinity of the EPD films. It is important to note that the thickness of the deposited films should strongly influence the broadness of the peaks. In any way, the broad peak detected at the $2 \theta$ angle of $11^{\circ}$ in both CMBF30s and TMBF30s patterns can be assigned to the presence of the octahedral $\mathrm{Mo}_{6}$ cluster units of nanometer size in the film ${ }^{42}$. It can be explained that the closedpacking of the nano-sized metal clusters with very low ordering in the film, which gives this amorphous-like peak, occurred during the electrophoretic deposition.

The recognition of the chemical vibrations in $\boldsymbol{C M B P}, \boldsymbol{T M B P}$, and the Mo6 cluster films (CMBF30s and TMBF30s) by FTIR spectroscopy is shown in Fig. 4. In the case of the TMBF30s film, the disappearance of the butyl vibrational band (from 1500 to $750 \mathrm{~cm}^{-1}$ ) and C$\mathrm{H}$ stretch vibrational band (from 2900 to $2800 \mathrm{~cm}^{-1}$ ) is clearly observed, which supports the hypothesis of the separation of the $\mathrm{TBA}^{+}$ions and $\left[\mathrm{Mo}_{6} \mathrm{Br}_{8}^{\mathrm{i}} \mathrm{Br}^{\mathrm{a}}{ }_{6-\mathrm{x}} \mathrm{L}_{\mathrm{x}}^{\mathrm{a}}\right]^{\mathrm{x}-2}$ cluster units during the EPD process. The intensity of O-H vibrational band in the wavenumber range between $3600 \mathrm{~cm}^{-}$ ${ }^{1}\left(v_{3}\right)$ and $3200 \mathrm{~cm}^{-1}$ sharply increases, continuously including a stretching vibration $\left(v_{3}\right)$ at 3600 $\mathrm{cm}^{-1}$, a stretching vibration $\left(v_{1}\right)$ at $3450 \mathrm{~cm}^{-1}$ and an overtone of the bending vibration $\left(2 v_{2}\right)$ at $3250 \mathrm{~cm}^{-1}$. The TMBF30s and CMBF30s films have similar FTIR spectra consisting of the asymmetric $\mathrm{O}-\mathrm{H}$ stretch vibrational band $\left(2 v_{2}\right)$ at $3250 \mathrm{~cm}^{-1}$, combined bending modes $\left(v_{2}\right)$ and vibrations $\left(v_{\mathrm{L}}\right)$ of the $\mathrm{H}-\mathrm{O}-\mathrm{H}$ mode at $2304 \mathrm{~cm}^{-1}$, and the $\mathrm{H}-\mathrm{O}-\mathrm{H}$ bending mode at $1589 \mathrm{~cm}^{-1}$, $1400 \mathrm{~cm}^{-1}\left(v_{2}\right)$ and $792 \mathrm{~cm}^{-1}\left(v_{\mathrm{L}}\right)^{43}$. The band assigned to O-H of the H-O-H stretch vibration $\left(v_{3}\right)$ at $3527 \mathrm{~cm}^{-1}$ in the $\boldsymbol{C M B P}$ sample, representing the adsorbed free $\mathrm{H}_{2} \mathrm{O}$ molecules, shifted to the $\mathrm{O}-\mathrm{H}$ of the H-O-H stretch vibration $\left(2 v_{2}\right)$ at $3250 \mathrm{~cm}^{-1}$ in the CMBF30s film, the signal of the hydrogen bond ${ }^{44-46}$. For this reason, we assumed that the $\mathrm{Br}$ apical ligands were exchanged by the $\mathrm{H}_{2} \mathrm{O}$ molecules or $\mathrm{OH}^{-}$groups, consequently, new hydrogen bonds were formed in the Mo6 cluster film prepared by the EPD process. In addition, the obvious increase in the intensity of the $\mathrm{O}-\mathrm{H}$ vibrational band in the FTIR spectrum originated from the increase of the $\mathrm{H}_{3} \mathrm{O}^{+}$cation absorption in the film, which would be generated on the surface of the ITO glass anode by the oxidization reaction of the $\mathrm{H}_{2} \mathrm{O}$ molecules contaminated in the suspension in order to neutralize 
the negative charges of the $\left[\mathrm{Mo}_{6} \mathrm{Br}_{8}{ }_{8} \mathrm{Br}^{\mathrm{a}}{ }_{6-\mathrm{x}} \mathrm{L}_{\mathrm{x}}^{\mathrm{a}}\right]^{\mathrm{x}-2}$ cluster molecules ${ }^{21}$.

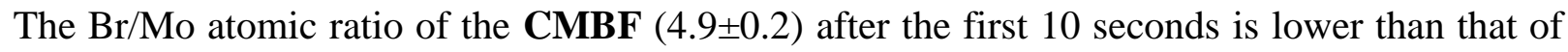
the TMBF (7.2 \pm 0.3 ) at $7.5 \mathrm{~V}$ (Fig. 1a), which suggests that the $\mathrm{Br}$ apical ligands of $\boldsymbol{C M B P}$ are less labile than $\boldsymbol{T M B P}$ probably due to a limited exchange by the $\mathrm{H}_{2} \mathrm{O}$ molecules or $\mathrm{OH}^{-}$groups in the MEK solution. Thus, the $\boldsymbol{C M B P}$ suspension was selected as the precursor solution to prepare the $\mathrm{Mo}_{6}$ cluster film (CMBF30s) that was investigated for the chemical elements through the XPS and EDX measurements. In order to elucidate the difference in the structure and chemical components of the $\left[\mathrm{Mo}_{6} \mathrm{Br}^{\mathrm{i}}{ }_{8} \mathrm{Br}^{\mathrm{a}}{ }_{6-\mathrm{x}} \mathrm{L}_{\mathrm{x}}^{\mathrm{a}}\right]^{\mathrm{x}-2}$ cluster unit, the XPS spectra of the $\mathrm{O} 1 \mathrm{~s}$ (Fig. 5a), Cs 3d and 4d (Fig. 5b), Mo 3d (Fig. 5c) and Br 3d region (Fig. 5d, 5e and 5f) of the $\mathrm{Cs}_{2} \mathrm{Mo}_{6} \mathrm{Br}_{14}$ powder $(\boldsymbol{C M B P})$ and the $\mathrm{Mo}_{6}$ film $(\mathbf{C M B F 3 0 s})$ were recorded and analyzed. The results are presented in Figure 5 and Table 3.

The XPS spectra of $\mathrm{O} 1 \mathrm{~s}$ evidences a peak at $533.2 \mathrm{eV}$ for both samples (Fig. 5a), which is assigned to either $\mathrm{H}_{2} \mathrm{O}$ molecule or $\mathrm{OH}^{-}$group. However, the intensity of the signal of $\mathrm{O} 1 \mathrm{~s}$ atoms in the CMBF30s film is higher than that in $\boldsymbol{C M B P}$. This result supports the substitution of apical $\mathrm{Br}$ atoms by $\mathrm{H}_{2} \mathrm{O}$ molecules or $\mathrm{OH}^{-}$groups during the dissolution process and the absorption of the $\mathrm{H}_{3} \mathrm{O}^{+}$cations during the deposition on an ITO glass. The XPS spectra of Cs $4 \mathrm{~d}$ evidences the peaks at $738 \mathrm{eV}\left(3 \mathrm{~d}_{3 / 2}\right), 724 \mathrm{eV}\left(3 \mathrm{~d}_{5 / 2}\right), 76.1 \mathrm{eV}\left(4 \mathrm{~d}_{3 / 2}\right)$ and $78.4 \mathrm{eV}\left(4 \mathrm{~d}_{5 / 2}\right)$ only for the $\boldsymbol{C M B P}$ sample (Fig. 5b), confirming (i) the presence of Cs atoms as counter cation in the precursor and (ii) the absence of Cs atoms in the film after the EPD process. The Mo 3d XPS spectra show equivalent peak intensity at $229.5\left(3 \mathrm{~d}_{5 / 2}\right)$ and $233 \mathrm{eV}\left(3 \mathrm{~d}_{3 / 2}\right)$ for both the $\boldsymbol{C M B P}$ and CMBF30s samples (Fig. 5c). Consistently with the XRF and EDS results, it confirms the presence of octahedral Mo6 clusters in the film after the deposition.

The peaks in the $\mathrm{Br} 3 \mathrm{~d}$ region of the $\boldsymbol{C M B P}$ and $\mathbf{C M B F 3 0 s}$ samples have relatively similar values (Fig. 5d). The peaks at $70.4 \mathrm{eV}$ and $68.5 \mathrm{eV}$ are assigned to the inner $\mathrm{Br}$ atoms and terminal apical $\mathrm{Br}$ atoms, respectively. While the peak intensities corresponding to the inner $\mathrm{Br}$ atoms of the $\boldsymbol{C M B P}$ and CMBF30s samples are equivalents, those of the $\mathrm{Br}$ atoms at the face-capping apical position are clearly different, as confirmed by their deconvolutions (Fig. 5e and 5f). Indeed, a reduction of the $\mathrm{Br} 3 \mathrm{~d}_{5 / 2}$ peak intensity at $68.5 \mathrm{eV}$ of apical $\mathrm{Br}$ atoms is clearly observed for the CMBF30s sample. Similar feature was also observed for the Mo6 clusters immobilized on graphene oxide ${ }^{8}$. It can be interpreted as a new valence linking between the Mo6 octahedral clusters and $\mathrm{OH}^{-}$functional groups by the removal of apical $\mathrm{Br}$ atoms from the cluster unit.

The atomic ratio of $\boldsymbol{C M B P}$ sample estimated from XPS spectra of $\mathrm{Br} 3 \mathrm{~d}$ and $\mathrm{Mo} 3 \mathrm{~d}$ is 14.1/6 $\approx$ 2.35). This value is very close to the theoretical index (2.33), while that in the CMBF30s sample is lower: $12.1 / 6(\approx 2)$. It indicates that in average each octahedral $\left[\mathrm{Mo}_{6} \mathrm{Br}_{8}{ }_{8} \mathrm{Br}_{6}^{\mathrm{a}}\right]^{2-}$ cluster unit deposited in the film lost $2 \mathrm{Br}$ atoms (Table.3). This ratio is inferior to that obtained from the XRF measurements (Fig. 1), probably due to the free $\mathrm{Br}^{-}$anions lost during the preparation of the XPS measurement. Consequently, only the $\mathrm{Br}$ atoms directly linking with the Mo6 clusters are then detected by XPS. 
From XPS and FTIR analyses, it could be conclude that the dissolution in the MEK solvent and the EPD process induces the substitution of two $\mathrm{Br}$ apical ligands from the $\left[\mathrm{Mo}_{6} \mathrm{Br}_{8}{ }_{8} \mathrm{Br}_{6}^{\mathrm{a}}\right]^{2-}$ cluster units, which are replaced by two $\mathrm{OH}^{-}$groups or $\mathrm{H}_{2} \mathrm{O}$ molecules originated from the solvent to form either $\left[\mathrm{Mo}_{6} \mathrm{Br}_{8}{ }_{8} \mathrm{Br}^{\mathrm{a}}{ }_{6-\mathrm{x}}(\mathrm{OH})_{\mathrm{x}}^{\mathrm{a}}\right]^{2-}$ or $\left[\mathrm{Mo}_{6} \mathrm{Br}_{8}{ }_{8} \mathrm{Br}^{\mathrm{a}}{ }_{4}\left(\mathrm{H}_{2} \mathrm{O}\right)^{\mathrm{a}}{ }_{2}\right]$ cluster units. Both of them are known to exhibit a stable octahedral structure ${ }^{49-50}$.

The chemical analysis, shape and size diameter of the first deposited cluster units inside the EPD film (CMBF30s) were clearly characterized by the TEM-EDX and STEM images (Fig. 6). The EDX-TEM mapping (Fig. 6a) shows homogenous distribution of $\mathrm{Br}$ and Mo atoms, while the presence of Cs atoms is not significantly recognized. The later point supports the absence of Cs atoms previously suggested by XRF and XPS analyses. The TEM images indicate that the CMBF30s sample consists of many crystallized nanoparticles of average diameter about $6 \mathrm{~nm}$, homogeneously distributed near the substrate (Fig. $6 \mathrm{~b}$ and $6 \mathrm{c}$ ). Considering that a single cluster unit presents an average volume of $1.2 \mathrm{~nm}^{342}$, it can be deduced that a nanoparticle of $6 \mathrm{~nm}$ diameter is formed by less than $90\left[\mathrm{Mo}_{6} \mathrm{Br}_{8}{ }_{8} \mathrm{Br}^{\mathrm{a}}{ }_{6-\mathrm{x}}(\mathrm{OH})_{\mathrm{x}}^{\mathrm{a}}\right]^{2-}$ or $\left[\mathrm{Mo}_{6} \mathrm{Br}^{\mathrm{i}}{ }_{8} \mathrm{Br}_{4}^{\mathrm{a}}{ }_{4}\left(\mathrm{H}_{2} \mathrm{O}\right)^{\mathrm{a}}{ }_{2}\right]$ cluster units, the number of cluster units per nanoparticle being dependent on the cluster unit density. Considering that in MEK solution, the cluster units are linked together by hydrogen bonds, it leads to the formation of bigger negative charged spherical particles, which are accumulated on the electrode surface through the effective impact of the electric field to form the multilayers. Therefore, the structure in the first $100 \mathrm{~nm}$ layer is proposed to be an arrangement of $\left[\mathrm{Mo}_{6} \mathrm{Br}_{8}{ }_{8} \mathrm{Br}^{\mathrm{a}}{ }_{6-\mathrm{x}}(\mathrm{OH})^{\mathrm{a}}{ }_{\mathrm{x}}\right]^{2-}$ and $\left[\mathrm{Mo}_{6} \mathrm{Br}_{8}{ }_{8} \mathrm{Br}^{\mathrm{a}}{ }_{4}\left(\mathrm{H}_{2} \mathrm{O}\right)^{\mathrm{a}}{ }_{2}\right]$ spherical nanoparticles of $6 \mathrm{~nm}$ diameter. Consequently, the micron-sized layer is formed by the closed-pack stacking of different types of the species: $\left(\mathrm{H}_{3} \mathrm{O}\right)^{+}$cations, free $\mathrm{Br}^{-}$anions, spherical nanoparticles containing a large number of $\left[\mathrm{Mo}_{6} \mathrm{Br}_{8}{ }_{8} \mathrm{Br}^{\mathrm{a}}{ }_{6-\mathrm{x}}(\mathrm{OH})_{\mathrm{x}}^{\mathrm{a}}\right]^{2-}$ and $\left[\mathrm{Mo}_{6} \mathrm{Br}_{8}{ }_{8} \mathrm{Br}^{\mathrm{a}}{ }_{4}\left(\mathrm{H}_{2} \mathrm{O}\right)^{\mathrm{a}}{ }_{2}\right]$ cluster units.

Based on the variation in the Br/Mo atomic ratios as a function of the applied voltage and deposition time and the modifications of the chemical linking observed by FTIR, XPS and TEM, we propose the following mechanism for the fabrication of the Mo6 cluster film by the EPD process. In the first seconds of the EPD process, high mobile $\mathrm{Br}^{-}$anions (originated from $\mathrm{OH}^{-}$to $\mathrm{Br}^{-}$substitution in MEK solution) move toward the ITO glass anode in the electric field to form a $\mathrm{Br}^{-}$rich sublayer. The $\left[\mathrm{Mo}_{6} \mathrm{Br}_{8}{ }_{8} \mathrm{Br}^{\mathrm{a}}{ }_{6-\mathrm{x}}(\mathrm{OH})^{\mathrm{a}}{ }_{\mathrm{x}}\right]^{2-}$ cluster units neutralized by $\mathrm{H}_{3} \mathrm{O}^{+}$cations move towards the ITO glass and form $\left(\mathrm{H}_{3} \mathrm{O}\right)_{2}\left[\mathrm{Mo}_{6} \mathrm{Br}^{\mathrm{i}}{ }_{8} \mathrm{Br}^{\mathrm{a}}{ }_{4}(\mathrm{OH})^{\mathrm{a}}{ }_{2}\right]$ assemblies. Due to lower $\mathrm{pH}$ close to the electrode, these later are quickly protonated to form $\left[\mathrm{Mo}_{6} \mathrm{Br}^{\mathrm{i}}{ }_{8} \mathrm{Br}_{4}^{\mathrm{a}}{ }_{4}\left(\mathrm{H}_{2} \mathrm{O}\right)^{\mathrm{a}}{ }_{2}\right]$ neutral cluster units. Some the $\left[\mathrm{Mo}_{6} \mathrm{Br}_{8}{ }_{8} \mathrm{Br}_{4}^{\mathrm{a}}\left(\mathrm{H}_{2} \mathrm{O}\right)^{\mathrm{a}}{ }_{2}\right]$ and $\left(\mathrm{H}_{3} \mathrm{O}\right)_{2}\left[\mathrm{Mo}_{6} \mathrm{Br}^{\mathrm{i}}{ }_{8 \mathrm{Br}^{\mathrm{a}}}{ }_{4}(\mathrm{OH})^{\mathrm{a}}{ }_{2}\right]$ cluster units interact together by hydrogen bonds to form approximately 6-nm size nanoparticles. The outer layers would mostly contain the $\left(\mathrm{H}_{3} \mathrm{O}\right)_{2}\left[\mathrm{Mo}_{6} \mathrm{Br}_{8}{ }_{8} \mathrm{Br}^{\mathrm{a}}{ }_{4}(\mathrm{OH})^{\mathrm{a}}{ }_{2}\right]$ cluster units which are simply packed by the EPD process (high velocity and collision of clusters). In summary, the Mo6 film is a nanocomposite material with a multilayer structure made by the stacking of $\mathrm{Br}^{-}$anions, $\left[\mathrm{Mo}_{6} \mathrm{Br}_{8}{ }_{8} \mathrm{Br}_{4}{ }_{4}\left(\mathrm{H}_{2} \mathrm{O}\right)^{\mathrm{a}}{ }_{2}\right]$ and $\left(\mathrm{H}_{3} \mathrm{O}\right)_{2}\left[\mathrm{Mo}_{6} \mathrm{Br}_{8}{ }_{8} \mathrm{Br}_{4}{ }_{4}(\mathrm{OH})^{\mathrm{a}}{ }_{2}\right]$ cluster units. A schematic representation is shown in Figure 7. It is important to note that in the proposed model, the nature of the cations, 
namely $\mathrm{Cs}^{+}$or $\mathrm{TBA}^{+}$, of the initial powder precursors does not seem to play a key role at the surface of the electrode. These cations seem to play only an important role in the dissolution of metal cluster in the solvent, and consequently, on the rate of the deposition and thickness.

\section{Conclusions}

This study describes on the preparation, and chemical, structural and optical analyses of smooth Mo6 cluster-based films deposited by the EPD process from the $\mathrm{Cs}_{2} \mathrm{Mo}_{6} \mathrm{Br}_{14}$ and (TBA) ${ }_{2} \mathrm{Mo}_{6} \mathrm{Br}_{14}$ cluster compounds in the MEK solution. The combination of X-ray analyses, electron microscopy and optical characterizations allow us to propose for the first time a mechanism for the multilayer structure deposition process of the metal atom clusters. The deposition of a Brrich layer during the first seconds of the EPD process is proved through the determination of the $\mathrm{Br} / \mathrm{Mo}$ atomic ratio in relation to the deposition time and applied voltages. Moreover, three important points should be pointed out: (i) the exchange of $2 \mathrm{Br}$ apical ligands by $\mathrm{OH}^{-}$or $\mathrm{H}_{2} \mathrm{O}$, (ii) the existence of two kinds of clusters in the $\mathrm{Mo}_{6}$ film, i.e., $\left[\mathrm{Mo}_{6} \mathrm{Br}^{\mathrm{i}}{ }_{8} \mathrm{Br}_{4}^{\mathrm{a}}{ }_{4}\left(\mathrm{H}_{2} \mathrm{O}\right)^{\mathrm{a}}{ }_{2}\right.$ ] and $\left[\mathrm{Mo}_{6} \mathrm{Br}_{8}{ }_{8} \mathrm{Br}_{4}^{\mathrm{a}}(\mathrm{OH})_{2}^{\mathrm{a}}\right]^{2-}$ paired with two $\left(\mathrm{H}_{3} \mathrm{O}\right)^{+}$, and (iii) the exchange of $\mathrm{Cs}^{+}$and $\mathrm{TBA}^{+}$cations by $\mathrm{H}_{3} \mathrm{O}^{+}$in order to keep a neutral charge. Finally, the films present a high transmittance in the visible range and strong absorption in UV and NIR ranges.

\section{Acknowledgement}

This study was carried out as part of the France-Japan international collaboration framework through the Laboratory for Innovative Key Materials and Structures (UMI 3629-LINK Center). The study was financially supported by the National Institute for Materials Science (NIMS), Saint-Gobain (France), CNRS and Université de Rennes 1 (UMR 6226). The authors wish to thank David Lechevalier and Dr. Mari Kono of Saint-Gobain KK (Tokyo, Japan) involved in LINK and related activities. We would like to thank Dr. Hirohito Ohata at NIMS for his help with the XPS measurements, Dr. Yoshio Matsui for his help with the STEM measurements and Dr. Chika Matsunaga at AIST for her valuable comments about the EPD experiments. The authors thank the ScanMAT platform at the University of Rennes 1 for the FE-SEM image (Figure 2c).

\section{References}

1. R. Chevrel, M. Sergent, and J. Prigent, J. Solid State Chem., 3, 515 (1971).

2. O. Pena, Physical C: Superconductivity and its Applications, 514, 95 (2015).

3. S. Cordier, F. Dorson, F. Grasset, Y. Molard, B. Fabre, H. Haneda, T. Sasaki, M. Mortier, A. Girard, and C. Perrin, J. Clust. Sci., 20, 9 (2009).

4. S. Cordier, F. Grasset, R. Boukherroub, N. Saito, H. Haneda, Y. Molard, S. Ravaine, M. Mortier, M. Amela-Cortes and N. Ohashi, J. Inorg. Organomet. Polym., 25 (2), 189 (2015).

5. S. Cordier, K. Kirakci, D. Mery, C. Perrin, and D. Astruc, Inorganica Chimica Acta, 359 (6), 
1705 (2006).

6. X. Zarate, E. Schott, L. A. Soto, and R. R. Tagle, Chem. Phys. Let., 567, 39 (2013).

7. K. Kirakci, P. Kubat, K. Fejfarovaa, J. Martincik, M. Nikl, and K. Lang, Inorg. Chem., 55 (2), 803 (2016).

8. P. Kumar, H. P. Mungse, S. Cordier, R. Boukherrou, O. P. Khatri, and S. L. Jain, Carbon, 94, 91 (2015).

9. A. Renaud, F. Grasset, B. Dierre, T. Uchikoshi, N. Ohashi, T. Takei, A. Planchat, L. Cario, S. Jobic, F. Odobel, and S. Cordier, Chem. Sel., 1, 2280 (2016).

10. Y. Zhao and R. R. Lunt, Adv. Energy. Mat., 3, 1143 (2013).

11. P. S. Kuttipillai, Y. Zhao, C. J. Traverse, R. J. Staples, B. G. Levine, and R. R. Lunt, Adv. Mater., 28, 320 (2016).

12. T. Aubert, F. Cabello Hurtado, M. A. Esnault, C. Neaime, D. Lebret Chauvel, S. Jeanne, P. Pellen, C. Roiland, L. L. Polles, N. Saito, K. Kimoto, H. Haneda, N. Ohashi, F. Grasset, and S. Cordier, J. Phys. Chem. C, 117, 20154 (2013).

13. A.O. Solovieva, Y. A. Vorotnikov, K. E. Trifonova, O. A. Efremova, A. A. Krasilnikova, K. A. Brylev, E. V. Vorontsova, P. A. Avrorov, L. V. Shestopalova, A. F. Poveshchenko, Y. V. Mironov and M. A. Shestopalov, J. Mater. Chem. B, 4, 4839 (2016).

14. C. Neaime, M. Amela-Cortes, F. Grasset, Y. Molard, S. Cordier, B. Dierre, M. Mortier, T. Takei, H. Haneda, M. Verelst, and S. Lechevallier, Phys. Chem. Chem. Phys, 18, 30166 (2016).

15. F. Cabello-Hurtado, M. D. Lozano-Baena, C. Neaime, A. Burel, S. Jeanne, P. Pellen-Mussi, S. Cordier and F. Grasset, J. Nanopart. Res., 18, 69 (2016).

16. M. A. Mikhailov, K. A. Brylev, P. A. Abramov, E. Sakuda, S. Akagi, A. Ito, N. Kitamura and M. N. Sokolov, Inorg. Chem, 55, 8437 (2016).

17. K. Kirakci, P. Kubat, J. Langmaier, T. Polivka, M. Fuciman, K. Fejfarovad and K.Lang, Dalton Trans, 42, 7224 (2013).

18. A. Beltran, M. Mikhailov, M. N. Sokolov, V. Perez-Laguna, A. Rezusta, M. J. Revillo and F. Galindo, J. Mater. Chem. B, 4, 5975 (2016).

19. T. Aubert, N. Nerambourg, N. Saito, H. Haneda, N. Ohashi, M. Mortier, S. Cordier, and F. Grasset, Part. Part. Syst. Charact., 30, 90 (2013).

20. T. G. Truong, B. Dierre, F. Grasset, N. Saito, N. Saito, T. K. N. Nguyen, K. Takahashi, T. Uchikoshi, M. Amela-Cortes, Y. Molard, S. Cordier and N. Ohashi, Sci. Technol. Adv. Mater., 17 (1), 443 (2016).

21. T. K. N. Nguyen, F. Grasset, B. Dierre, C. Matsunaga, S. Cordier, P. Lemoine, N. Ohashi and T.Uchikoshi, ECS J. Solid. State. Sci. and Technol., 5 (10), 178 (2016).

22. J. R. Jones, Acta Biomaterialia, 9, 4457 (2013).

23. X. Zhao, Q. Zhao, J. Yu and B. Liu, J. Non-Crystalline Solids, 354, 1424 (2008).

24. Kaishu Guan, Surf. Coat. Tech., 191, 155 (2005). 
25. T. Watanabe, A. Nakajima, R. Wang, M. Minabe, S. Koizumi, A. Fujishima, and K. Hashimoto, Thin Solid Films, 351, 260 (1999).

26. L. Besra and M. Liu, Progress in Mat. Sci., 52, 1 (2007).

27. I. Corni, M. P. Ryan, and A. R. Boccaccini, J. Eur. Ceram. Soc. 28, 1353 (2008).

28. A. C. Valdez and A. R. Boccaccini, Electrochimica Acta, 65, 70 (2012).

29. E. Ukaji, T. Furusawa, M. Sato and N. Suzuki, App. Surf. Sci., 254 (2), 563 (2007).

30. J. F. Limaa,P. C. de Sousa Filhoa, and O. A. Serraa, Ceram. Inter, 42(6), 7422 (2016).

31. N. Khayyat and H. R. Dizaji, Int. J. for Light and Electron Optics, 126 (23), 3936 (2015).

32. H. Liu, P. Sun, M. Feng, H. Liu, S. Yang, L. Wang and Z. Wang, App. Catal. B: Envi., 187, 1 (2016).

33. P. Uthirakumara, S. Muthulingama, R. Khanb, J. H. Yunb, H. S. Chob and I. H. Leeb, Mat. Lett. , 156, 191 (2015).

34. J. C. Boyer, M. P. Manseau, J. I. Murray and F. C. J. M. van Veggel, Langmuir, 26 (2), 1157 (2010).

35. L.R. Gaspar and M. Campos, Int. J. Pharm., 307 (2), 123 (2006).

36. N. Serpone, D. Dondi and A. Albini, Inorg. Chimica Acta, 360 (3), 794 (2007).

37. J. Dai, W. Gao, B. Liu, X. Cao, T. Tao, Z. Xie, H. Zhao, D. Chen, H. Ping and R. Zhang, Appl. Surf. Sci., 364, 886 (2016).

38. C. A. de Oliveira, M. F. Dario, F. D. Sarruf, I. F. A. Mariz, M. V. R.Velasco, C. Rosado and A. R. Baby, Colloid Surf. B: Biointerfaces, 140, 531 (2016).

39. T. Suresh, N. A. Murugan, V. Vijayakumar, P. Iniyavan, A. Srikanth and J. P. Jasinskid, J. Mol. Struct., 1099, 560 (2015).

40. H. B. Gray and A. W. Maverick, Solar Chemistry of Metal Complexes, Science, 214, 1201 (1981).

41. N. Saito, Y. Wada, P. Lemoine, S. Cordier, F. Grasset, T. Ohsawa, N. Saito, J. S. Cross, and N. Ohashi, Japanese J. of Appl. Phys., 55 (7), 075502 (2016).

42. K. Kirakci, S. Cordier, and C. Perrin, Z. Anorg. Allg. Chem, 631(2-3), 411 (2005).

43. S. Y. Venyaminov and F. G. Prendergast, Analy. Biochem., 248 (2), 234 (1997).

44. M. A. Mikhaylov, P. A. Abramova, V. Y. Komarova, and M. N. Sokolov, Polyhedron, 122, 241(2016).

45. Y. Furutani and H. Kandori, $B B A, \mathbf{1 8 3 7}, 598$ (2014).

46. R. J. Debus, $B B A, \mathbf{1 8 4 7}, 19$ (2015).

47. S. A. Al-Bataineh, L. G. Britcher and H. J. Griesser, Surf. Sci., 600, 952 (2006)

48. Y. Li, H. Chen, L. Y. Voo, J. Ji, G. Zhang, G. Zhang, F. Zhang and X. Fan, J. Mater. Chem., 22, 15021 (2012).

49. L. J. Guggenberger and W. Sleight, Minor. Chem., 8 (10), 2041 (1969).

50. Y.Q. Zheng, Y. Grin and H. G. Schnering, Z. Kristallogr. NCS, 213, 469 (1998). 


\section{Figure Captions}

Figure 1. The Br/Mo atomic ratio in the CMBF and TBMF films as a function of (a) the applied voltage for a deposition time of $10 \mathrm{~s}$, and (b) the deposition time for an applied voltage of $13 \mathrm{~V}$ and $17 \mathrm{~V}$, respectively.

Figure 2. The FE-SEM images of a) the surface and b) the cross-section of the $\mathrm{Mo}_{6}$ cluster films fabricated by EPD: CMBF20s at $13 \mathrm{~V}$ (top) and TMBF20s at $17 \mathrm{~V}$ (bottom). c) FE-SEM image of the cross-section of the CMBF40s film.

Figure 3. The XRD patterns of ITO glass, CMBP, TMBP, CMBF30s and TMBF30s samples.

Figure 4. The FT-IR spectra of $\boldsymbol{C M B P}, \mathbf{T M B P}, \mathbf{C M B F}$ and TMBF samples.

Figure 5. The XPS spectra of O 1s (a), Cs 3d and 4d (b), Mo 3d (c), and Br 3d region (d), deconvolution spectra of $\mathrm{Br} 3 \mathrm{~d}$ region of $\boldsymbol{C M B P}$ (e) and deconvolution spectra of $\mathrm{Br} 3 \mathrm{~d}$ of $\mathbf{C M B F}$ (f).

Figure 6. a) The EDX-TEM mapping of Cs, Mo and Br elements and b) TEM image (left) and STEM mode image (right) of the Mo6 cluster nanoparticles from film by EPD. c) Spherical Mo6 cluster nanoparticles included in the CMBF30s.

Figure 7. Schematic representation of the multilayered structure of Mo 6 cluster thin film 
Table 1. Physical properties of the $\boldsymbol{C M B P}$ and $\boldsymbol{T M B P}$ cluster suspensions in MEK solutions.

\begin{tabular}{|l|l|l|l|}
\hline $\begin{array}{l}\text { Suspension } \\
(5 \mathrm{~g} / \mathrm{L} \text { in MEK })\end{array}$ & $\begin{array}{l}\text { Conductivity } \\
(\mathrm{mS} / \mathrm{cm})\end{array}$ & $\begin{array}{l}\text { Zeta potential } \\
(\mathrm{mV})\end{array}$ & $\begin{array}{l}\text { DLS Particle size }(\mathrm{nm}) \\
(1 \mathrm{~g} / \mathrm{L} \text { in MEK })\end{array}$ \\
\hline CMBP & $0.33 \pm 0.01$ & $-21.0 \pm 1.2$ & $11 \pm 1$ \\
\hline TMBP & $0.30 \pm 0.03$ & $-26.4 \pm 1.7$ & $13 \pm 1$ \\
\hline
\end{tabular}

Table 2. Thickness (average) of the films deposited from the $C M B P$ and $T M B P$ cluster suspensions in MEK solutions for deposition times.

\begin{tabular}{|l|l|l|l|l|}
\hline \multirow{2}{*}{$\begin{array}{l}\text { Deposition time } \\
(\text { Second) }\end{array}$} & \multicolumn{4}{|l|}{ Thickness of films fabricated from MEK solution $(\mu \mathrm{m})$} \\
\cline { 2 - 5 } & $\mathrm{Cs}_{2} \mathrm{Mo}_{6} \mathrm{Br}_{14}$ solution $(13 \mathrm{~V})$ & \multicolumn{2}{|l|}{$(\mathrm{TBA})_{2} \mathrm{Mo}_{6} \mathrm{Br}_{14}$ solution $(17 \mathrm{~V})$} \\
\hline 10 & CMBF10s & $0.81 \pm 0.03$ & TMBF10s & $0.49 \pm 0.05$ \\
\hline 20 & CMBF20s & $1.05 \pm 0.09$ & TMBF20s & $1.23 \pm 0.09$ \\
\hline 30 & CMBF30s & $1.54 \pm 0.09$ & TMBF30s & $1.68 \pm 0.07$ \\
\hline 40 & CMBF40s & $1.89 \pm 0.08$ & TMBF40s & $1.29 \pm 0.12$ \\
\hline
\end{tabular}

Table 3. The percentage of the component elements in the $\boldsymbol{C M B P}$ and the CMBF30s films prepared at $13 \mathrm{~V}$ estimated by the peak analysis of the XPS measurements.

$\begin{array}{lllllll}\text { Element } & \text { O 1s } & \text { C 1s } & \text { Mo 3d Cs 4d Br 3d } \quad \text { Cs: Mo: Br (Wt.\% at.) }\end{array}$

$\begin{array}{lllllll}\boldsymbol{C M B P} & 4.9 \% & 22.3 \% & 20.2 \% & 5 \% & 47.6 \% & 1.5: 6.0: 14.1\end{array}$

$\begin{array}{lllllll}\text { CMBF30s } & 13.7 \% & 37.2 \% & 16.1 \% & - & 32.5 \% & 0: 6.0: 12.1\end{array}$


Figure 1. The Br/Mo atomic ratio in the CMBF and TBMF films as a function of (a) the applied voltage for a deposition time of 10s, and (b) the deposition time for an applied voltage of $13 \mathrm{~V}$ and $17 \mathrm{~V}$, respectively.
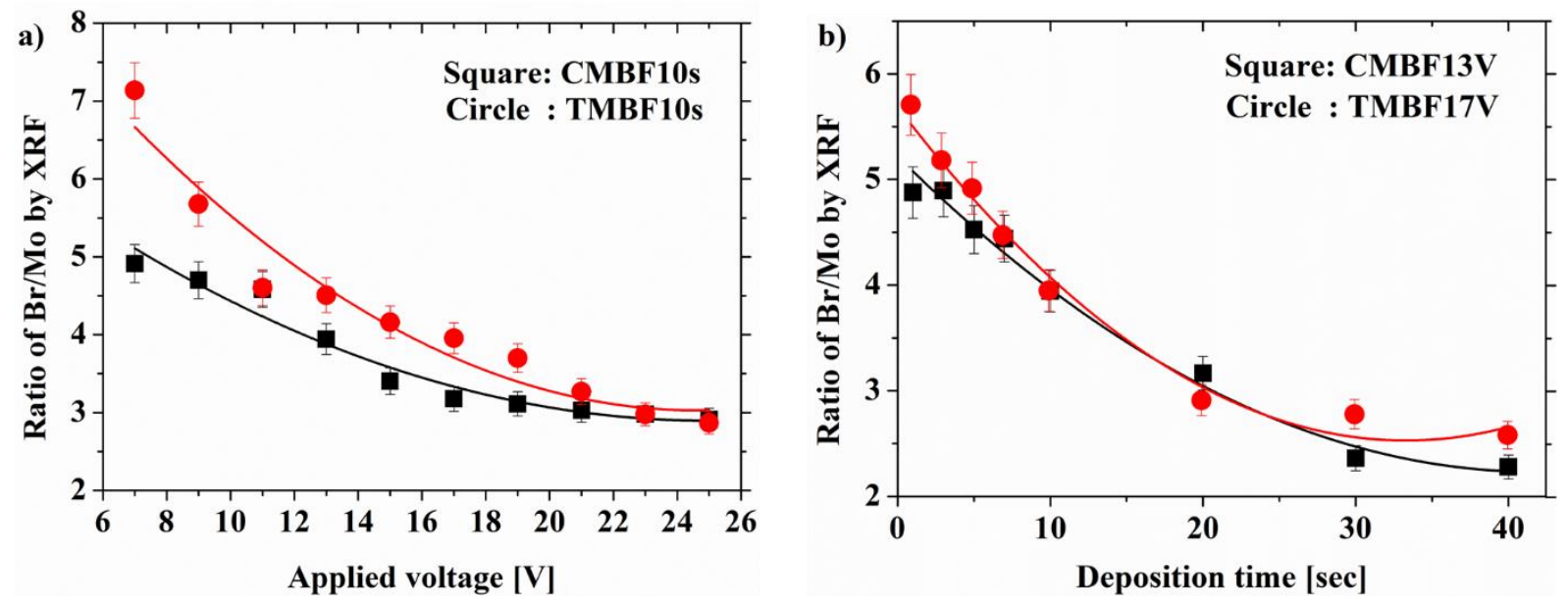
Figure 2. The FE-SEM images of a) the surface and b) the cross-section of the Mo6 cluster films fabricated by EPD: CMBF20s at 13 V (top) and TMBF20s at 17 V (bottom). c) FE-SEM image of the cross-section of the CMBF40s film.

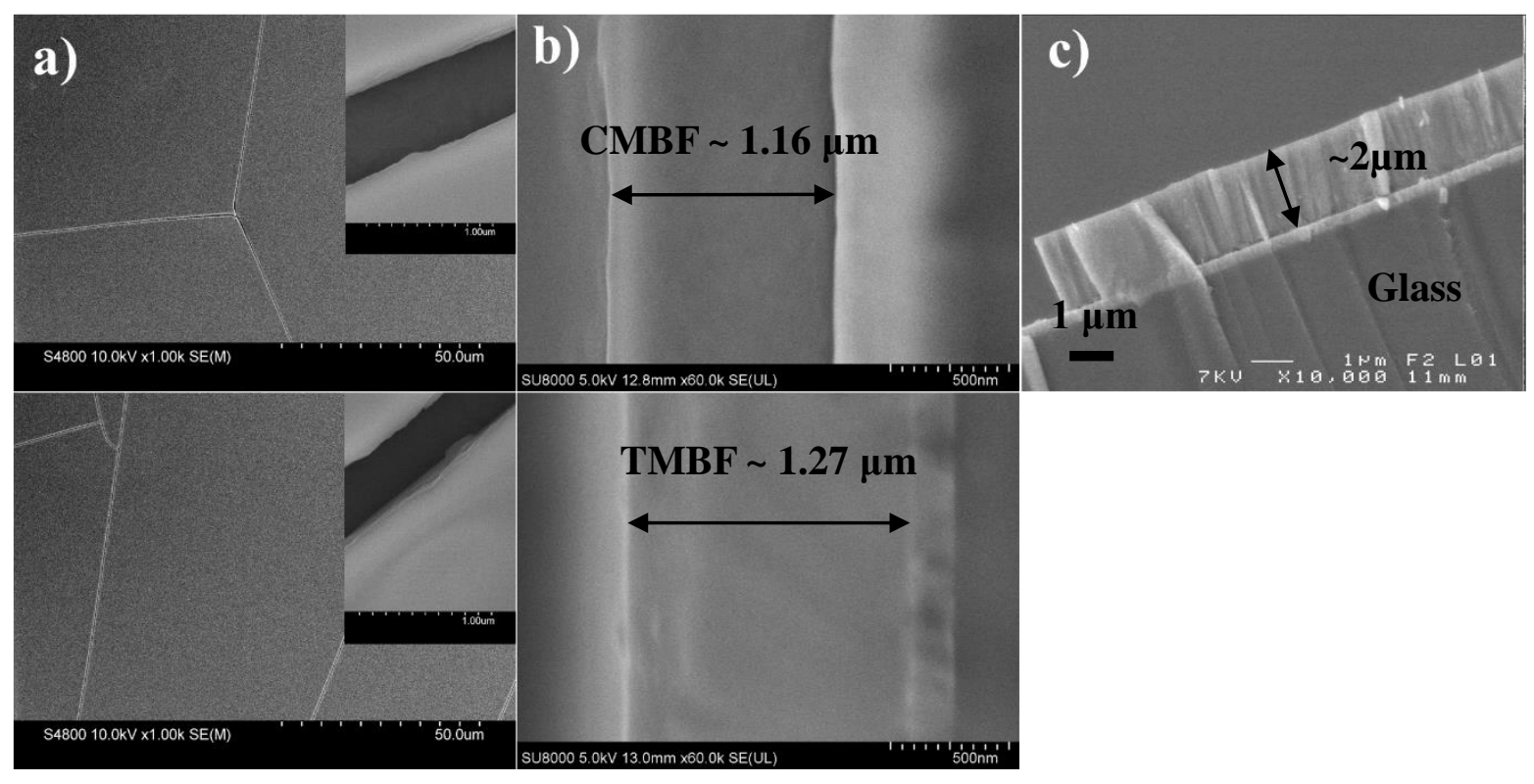


Figure 3. The XRD patterns of ITO glass, $\boldsymbol{C M B P}, \boldsymbol{T M B P}, \mathbf{C M B F 3 0 s}$ and TMBF30s samples.

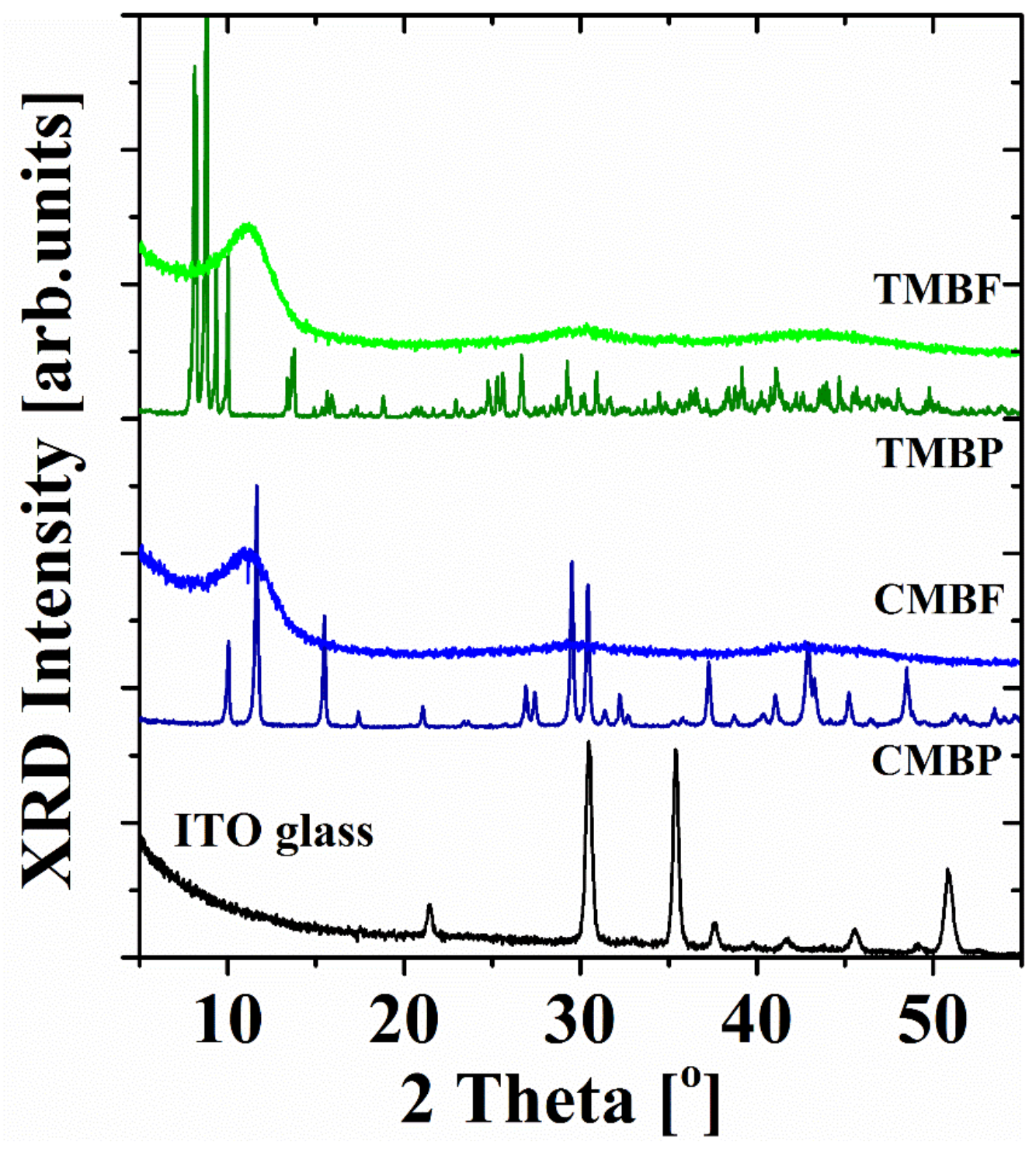


Figure 4. The FT-IR spectra of $\boldsymbol{C M B P}, \mathbf{T M B P}, \mathbf{C M B F}$ and TMBF samples.

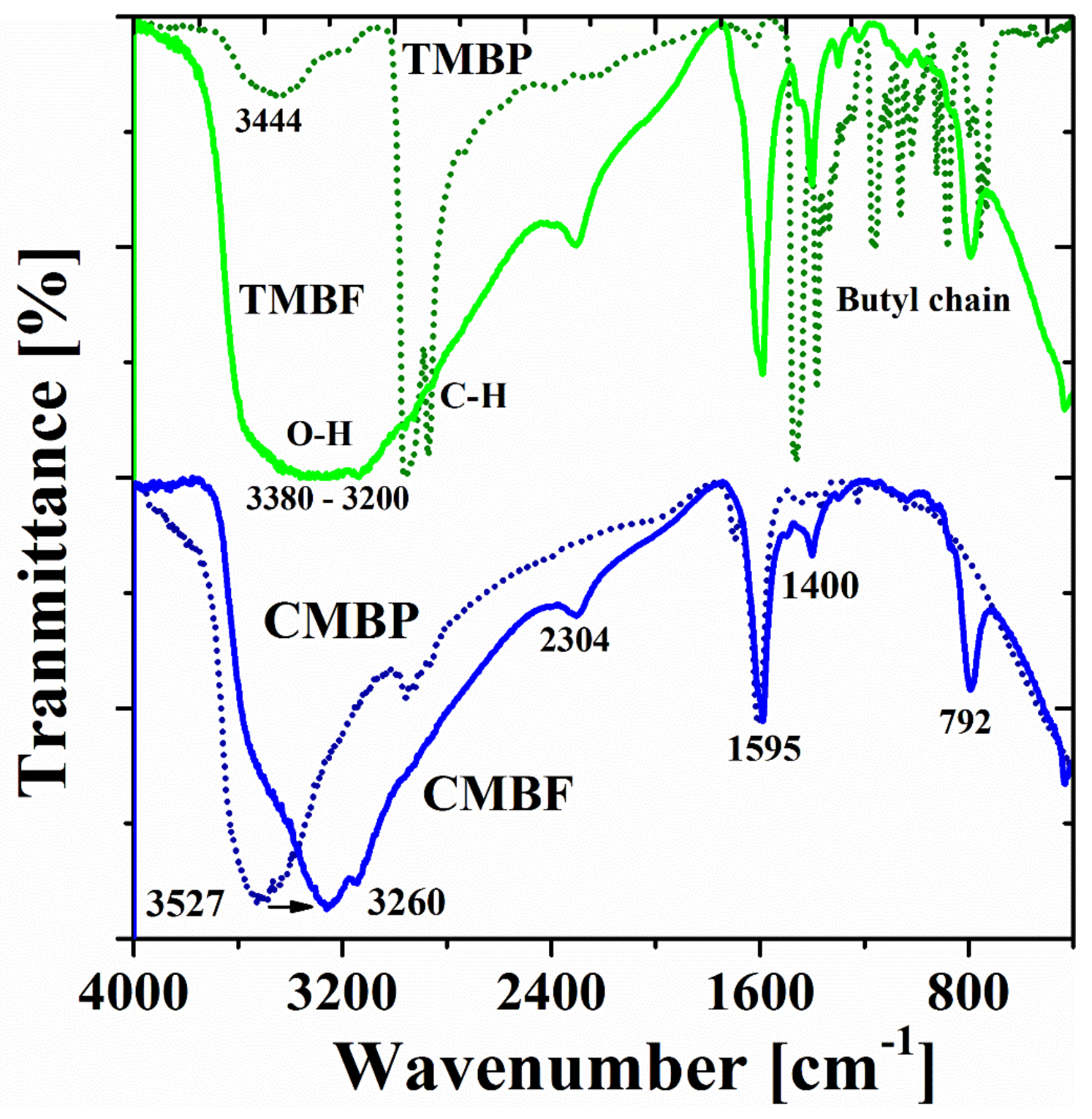


Figure 5. The XPS spectra of $\mathrm{O} 1 \mathrm{~s}$ (a), Cs 3d and 4d (b), Mo 3d (c), and Br 3d region (d), deconvolution spectra of $\mathrm{Br} 3 \mathrm{~d}$ region of $\boldsymbol{C M B P}(\mathrm{e})$ and deconvolution spectra of $\mathrm{Br} 3 \mathrm{~d}$ of $\mathbf{C M B F}$ (f).
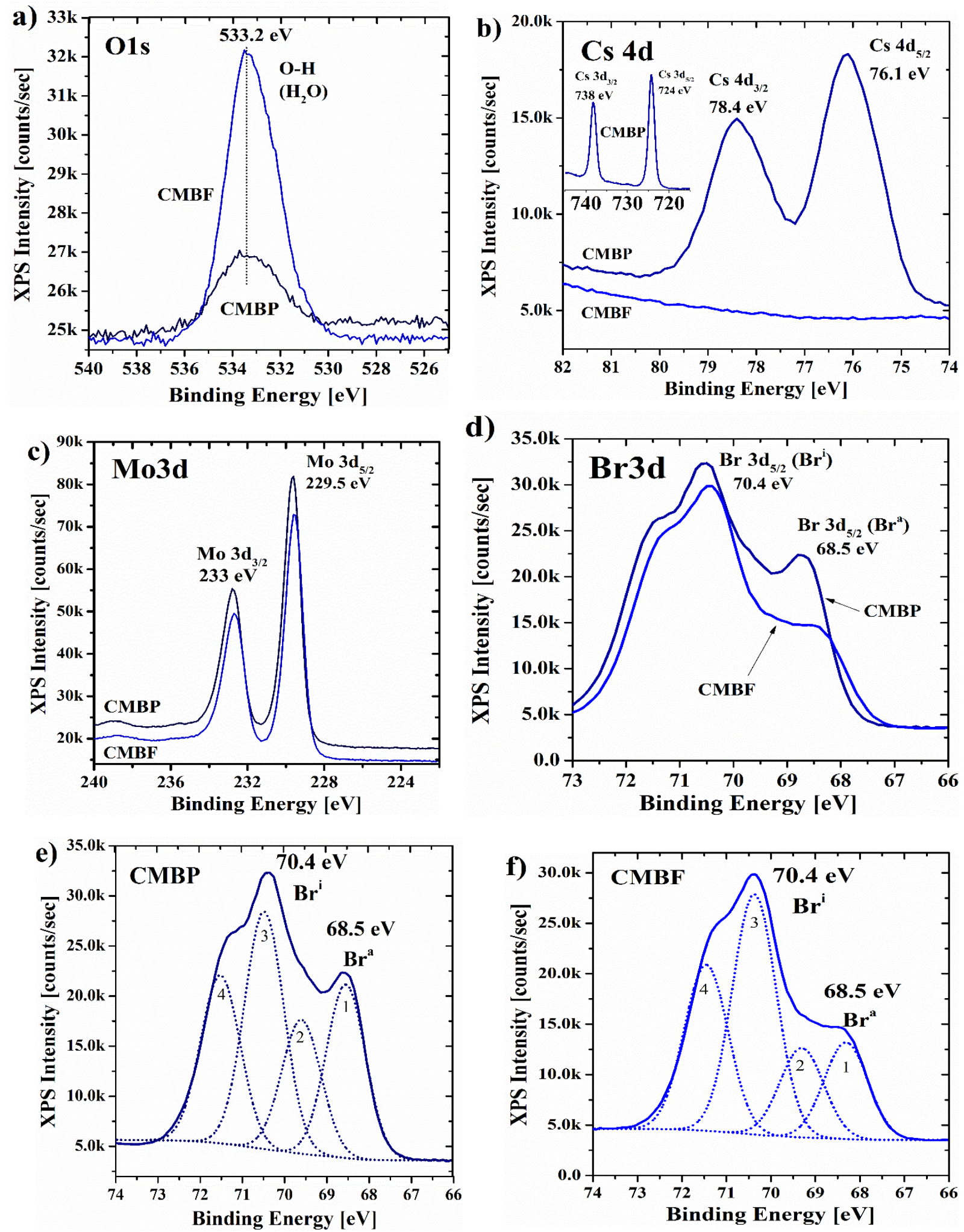
Figure 6. a) The EDX-TEM mapping of Cs, Mo and Br elements and b) TEM image (left) and STEM mode image (right) of the Mo6 cluster nanoparticles from film by EPD. c) Spherical Mo6 cluster nanoparticles included in the CMBF30s.

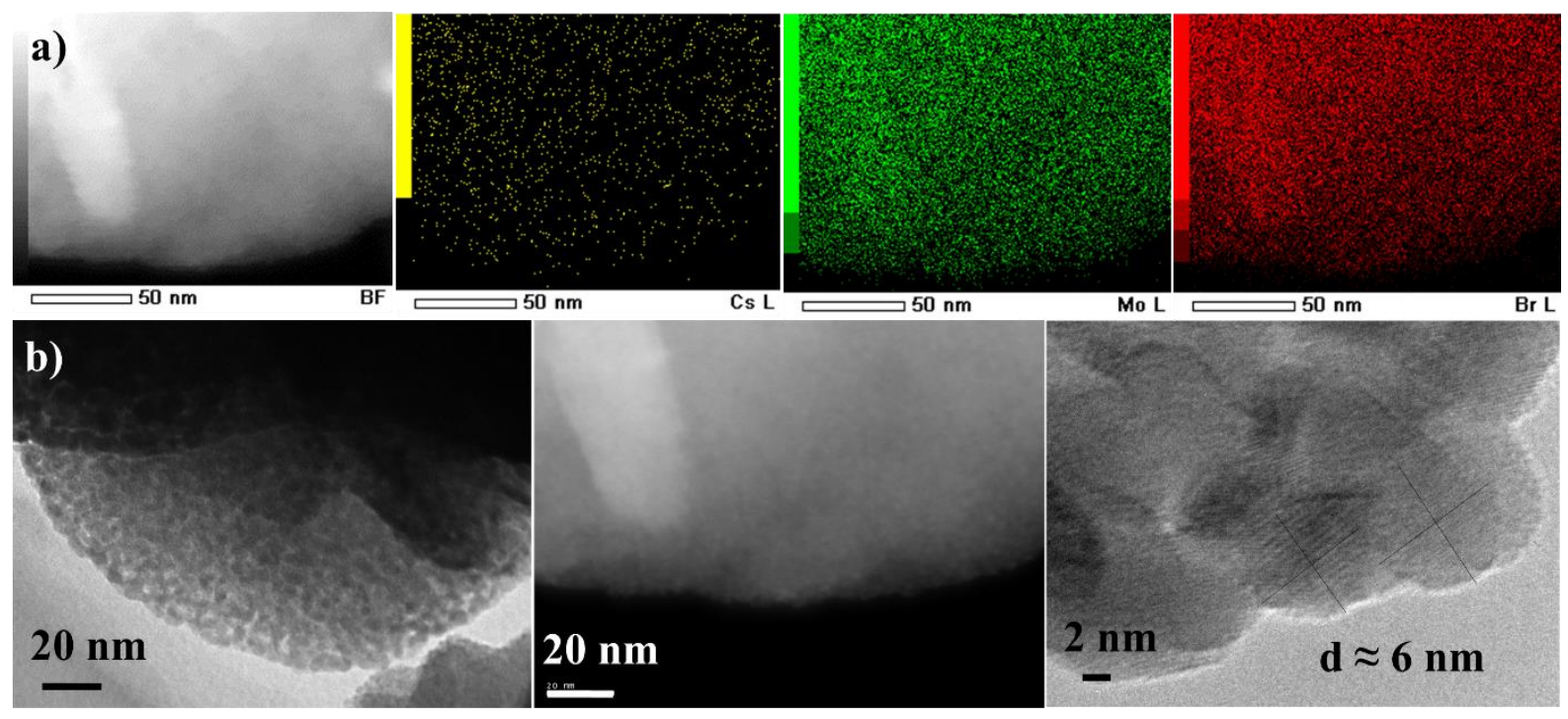


Figure 7. Schematic representation of the multilayered structure of Mo6 cluster thin film

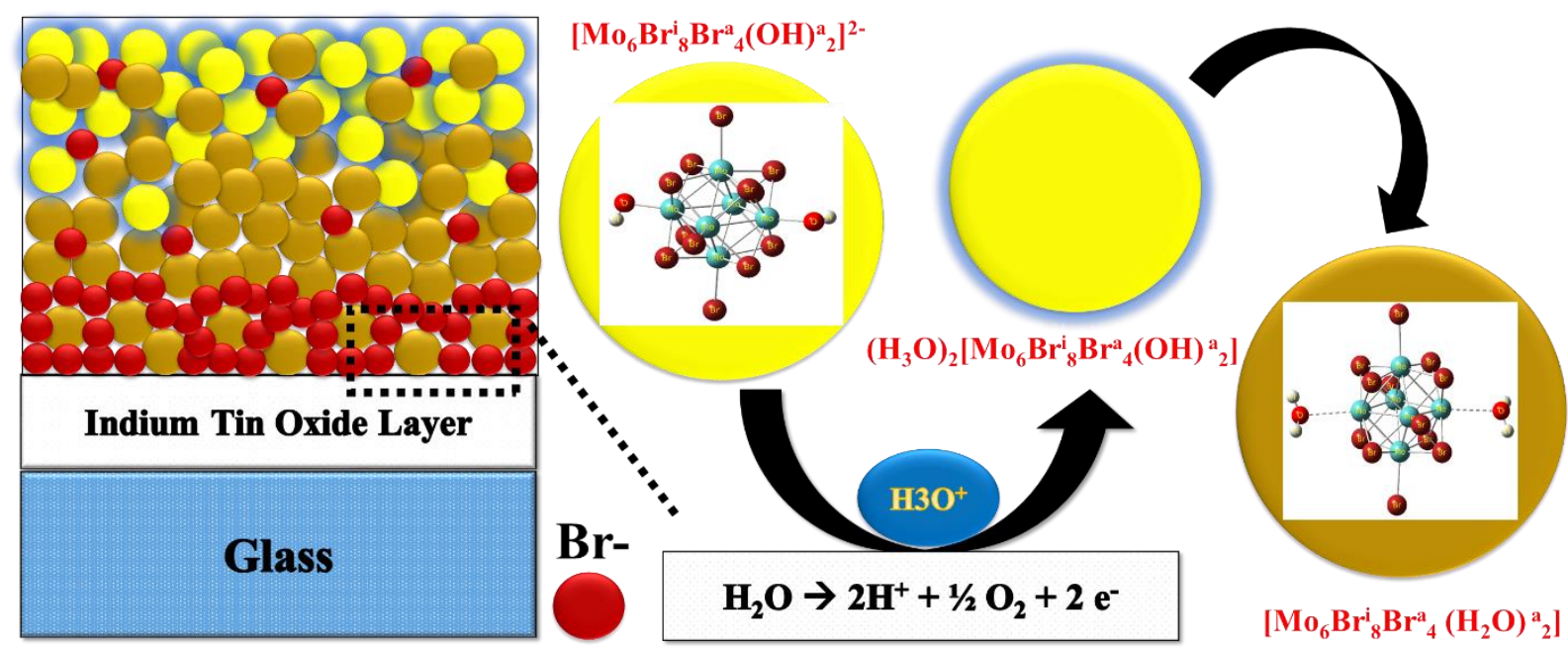

